\title{
FILMES COMESTÍVEIS: ASPECTOS GERAIS, PROPRIEDADES DE BARREIRA A UMIDADE E OXIGÊNIO
}

\author{
LUCIANA HELENA MAIA * \\ ALEXANDRE PORTE ** \\ VALÉRIA FRANÇA DE SOUZA **
}

\begin{abstract}
Apresenta breve revisão bibliográfica sobre filmes e revestimentos comestíveis, abordando sua produção e os diferentes tipos de filmes e revestimentos de proteína, lipídios e amidos. Discute as propriedades dos filmes como barreiras contra a transmissão de oxigênio e vapor de água. Conclui que o aperfeiçoamento e adaptação da estrutura físico-química e métodos de aplicação dos filmes e revestimentos às características composicionais dos produtos propiciará seu crescimento para outros segmentos da produção de alimentos.
\end{abstract}

\section{INTRODUÇÃO}

Semelhante às embalagens de alimentos, que já nos anos 5000 a.C. existiam na forma de cestas e bolsas confeccionadas com produtos de origem animal e vegetal, além de primitivos recipientes de cerâmica (SOROKA, 1995), os filmes comestíveis e revestimentos recentes não são senão o aperfeiçoamento de técnicas aplicadas desde longa data. $\mathrm{O}$ revestimento de laranjas e limões frescos com cera para retardar a desidratação foi praticado na China nos séculos XII e XIII (HARDENBURG, 1967). O processo de envolver alimentos em gordura com o intuito de reduzir a perda de umidade foi usado na Inglaterra no século XVI (LABUZA \& CONTRERAS-MEDELLIN, 1981). HARVARD e HARMONY propuseram a utilização de filmes de gelatina na preservação de carnes e outros gêneros alimentícios (KESTER \& FENNEMA, 1986). Na década de 50, emulsões de cera de carnaúba foram desenvolvidas para o revestimento de frutas e vegetais frescos (KAPLAN, 1986). Mesmo assim, foi nessas últimas décadas que ampliaram-se as pesquisas e a produção de filmes de revestimento para uso na indústria de alimentos, visando melhoria da qualidade e extensão da vida de prateleira de vários tipos de produtos.

* Economista Doméstica, Mestranda em Ciência e Tecnologia de Alimentos, Universidade Federal Rural do Rio de Janeiro (UFRRJ).

** Nutricionista, Mestrando em Ciência e Tecnologia de Alimentos, Universidade Federal Rural do Rio de Janeiro (UFRRJ). 
Os filmes comestíveis são películas de variadas espessuras constituídas por diferentes substâncias naturais e/ou sintéticas que se polimerizam e isolam o alimento, sem riscos à saúde do consumidor, uma vez que não são metabolizados pelo organismo e sua passagem pelo trato gastrointestinal se faz de maneira inócua.

Segundo KROCHTA \& DE MULDER-JOHNSTON (1997) filme comestível é definido como fina camada de material comestível, formado diretamente como revestimento, ou como revestimento pré-formado e colocado sobre o alimento ou entre seus componentes.

A função a ser desempenhada pelo filme depende do produto alimentício e principalmente do tipo de deterioração a que este produto está submetido (KESTER \& FENNEMA, 1986).

As principais funções dos filmes comestíveis são: inibir a migração de umidade, oxigênio, dióxido de carbono, aromas, lipídios e outros solutos; carrear aditivos alimentares e agentes antimicrobianos; melhorar a integridade mecânica e as características de manuseio de alimentos (KESTER \& FENNEMA, 1986; KROCHTA \& DE MULDER-JOHNSTON, 1997; NELSON \& FENNEMA, 1991).

Exemplos práticos destas características funcionais são dadas pôr diversos autores, como por exemplo, o uso de revestimentos de superfície para minimizar a difusão de sal para dentro do alimento, tal como camarão e caranguejo, durante seu congelamento em salmoura (GUILBERT, 1986).

ANDRES (1985) verificou que líquidos viscosos transformam-se em filmes protetores durante o aquecimento, diminuindo a quantidade de óleo absorvida pelo alimento. Também citou filmes que funcionam como barreira contra a evaporação da umidade em carnes, que resulta em perda de peso e de qualidade do produto, e ainda, filmes aplicados em pizzas prevenindo potenciais problemas com deslocamentos e perdas de ingredientes como azeitonas, fatias de tomate, etc. Resultados semelhantes foram encontrados por BALASUBRAMANIAM et al. (1997), os quais reduziram a perda de umidade e a quantidade de óleo de amendoim absorvida em almôndegas de frango fritas, usando filme de hidroxipropilmetilcelulose, que melhorou os efeitos acima mencionados a partir de 40 segundos de fritura entre 50 a $90{ }^{\circ} \mathrm{C}$.

RICO-PEÑA \& TORRES (1991) testaram a eficiência do filme comestível de metilcelulose/ácido palmítico (3:1), quanto à permeabilidade ao ácido sórbico e sorbato de potássio, que quando aplicados diretamente na superfície do alimento vão migrando para o interior e perdem seu efeito. $O$ filme retardou eficientemente esta migração, mas necessitou de atividade de água inferior a 0,8 e pH igual a 7,0 para promover alta retenção destes compostos. $O$ ácido sórbico e seus sais são agentes antimicrobianos 
usados em diversos produtos de origem animal, mas infelizmente, atividade de água superior a 0,9 exclui o uso do filme em muitos alimentos, limitando seu uso. Da mesma forma, o pH 7,0 está acima do pKa do ácido sórbico, logo o ácido apresenta-se na forma dissociada, cujo efeito antimicrobiano torna-se bastante reduzido.

NELSON \& FENNEMA (1991) avaliaram o uso de filme de metilcelulose na prevenção da migração de lipídios em produtos de confeitaria (como na migração de lipídios de baixo ponto de fusão e mais fluidos contidos em recheios de bombons para a cobertura de chocolate, alterando a sua textura, integridade física e conseqüentemente, sua aceitabilidade). Encontraram resposta positiva proporcional ao aumento da espessura do filme. Contudo, é necessário desenvolver espessura que seja ao mesmo tempo eficiente contra o transporte lipídico (<que $0,0056 \mathrm{~mm}$ ) e minimamente percebido pelo paladar humano.

Embora haja discordância entre alguns autores (MILLER \& KROCHTA, 1997; KROCHTA \& DE MULDER-JOHNSTON, 1997; KESTER \& FENNEMA, 1986) sobre a substituição de embalagens sintéticas por biopolímeros com boas propriedades mecânicas para aplicação em certos tipos de alimentos, razões econômicas, ambientais e de "marketing" têm incrementado o desenvolvimento e o consumo destes filmes poliméricos comestíveis. Isto porque podem diminuir a quantidade de embalagem sintética necessária ou transformar uma embalagem multicomponente em simples substância reciclável (MILLER \& KROCHTA, 1997; KROCHTA \& DE MULDER-JOHNSTON, 1997; KESTER \& FENNEMA, 1986).

GHORPADE et al. (1995) tentaram melhorar as características mecânicas de filme a base de isolado de proteína de soja com a inserção de óxido de polietileno, com o intuito de facilitar a degradação do material plástico. Entretanto houve aumento à permeabilidade de umidade diretamente proporcional ao acréscimo de óxido de polietileno.

Existem muitos aspectos a serem observados quanto às funções dos filmes comestíveis, os quais se devem a diversidade de tipos e combinações entre substâncias naturais e sintéticas que podem dar origem ao filme e afetar as suas propriedades.

O presente trabalho teve por objetivo enfocar dois dos principais interesses atuais no assunto, ou seja, as propriedades de transmissão de umidade e gases dos filmes.

\section{PRODUÇÃO DE FILMES COMESTÍVEIS}

Filmes e revestimentos comestíveis podem ser formados por diversos caminhos (KONDO \& VAN VALKENBURG, 1979), sendo um deles por 
coacervação. A coacervação é, por definição, a separação pela adição de uma substância ou pela variação da temperatura, de duas fases líquidas de um colóide: uma rica em colóide e outra quase isenta dele.

Para hidrocolóides, segundo KESTER \& FENNEMA (1986), os processos de formação incluem:

- coacervação simples - consiste na evaporação do solvente aquoso de um hidrocolóide, na adição de outro solvente não eletrolítico (ex. álcool), no qual o hidrocolóide é insolúvel e na adição de um eletrólito para causar salting-out, ligação cruzada ou alteração do pH;

- coacervação complexa - consiste na combinação de duas soluções hidrocolóides de cargas opostas, causando interação e precipitação de polímeros complexos;

- gelatinização térmica ou precipitação - que pode envolver o aquecimento de uma proteína causando desnaturação seguida por gelatinização (ex. albumina do ovo) ou precipitação, ou simplesmente o resfriamento de uma suspensão hidrocolóide quente, causando transformação sol-gel (ex. gelatina).

Tais processos resultam em revestimentos e filmes que são insolúveis em água e outros que são solúveis. Quando a insolubilidade do filme é desejada, esta pode ser alcançada pela adição de íons di- ou trivalentes (ex. ligação cruzada de alginato com cálcio), ajustamento de pH, exposição a irradiação ou tratamento térmico (KONDO \& VAN VALKENBURG, 1979).

Os filmes e revestimentos aplicados em alimentos são formados, geralmente, pela solução ou dispersão de um agente formador de filme, seguido de meio de separação deste agente do fluido transportador, ou pela solidificação do material formado de filme fundido (ex. lipídio). Outro meio utilizado é a aplicação do filme ou revestimento diretamente na superfície do alimento, mediante spray, recobrimento de filme fundido, ou imersão, ou alternativamente, o filme fundido ou em suspensão pode ser moldado ou extrusado para produzir filmes de sustentação (KESTER \& FENNEMA, 1986).

Estruturas poliméricas de cadeia longa são necessárias para produzir matrizes de filmes com apropriado poder coesivo (BANKER, 1966). O poder coesivo do filme é descrito pela estrutura e composição química do produto, natureza do solvente, presença de aditivos e das condições ambientais durante a formação do filme. Com o aumento da coesão estrutural geralmente há redução na flexibilidade, porosidade $e$ permeabilidade para gases, vapor e soluto dos filmes. Polaridade maior na cadeia de polímeros, bem como distribuição uniforme dos grupos polares ao longo da cadeia aumenta a coesão, devido a maior probalidade de 
ocorrer pontes de hidrogênio e interações iônicas entre as cadeias. Por exemplo, quando a pectina é parcialmente desmetoxilada para expôr o grupo carboxila podem ocorrer ligações cruzadas na presença de cátions divalentes, causando aumento no poder de coesividade e elasticidade dos filmes secos (MIERS et al., 1953).

As condições ambientais durante a formação dos filmes podem influenciar a coesão. A aplicação de solução formadora de filme em superfície de recebimento quente, produz filme mais coeso. No entanto, excessivas temperaturas, resultando em excessiva taxa de evaporação do solvente, durante a secagem do filme, pode prematuramente imobilizar as moléculas de polímeros destes para unirem-se num filme contínuo. Tal fato pode acarretar a formação de filme defeituoso, com cavidades ou espessuras não uniformes, aumentando a permeabilidade do filme (BANKER, 1966). Segundo KESTER \& FENNEMA (1986) o potencial para imobilização das cadeias de polímeros é maior em filmes formados por spray do que em filmes formados por moldagem ou imersão, devido a rápida evaporação dos solventes de suspensões de revestimentos atomizados.

PICKARD, RESS \& ELWORTH (1972) estudaram a influência da técnica de preparação de filmes nas propriedades de barreira de filmes copolímeros de etilcelulose-hidroxipropil e metilcelulose. Verificaram que filmes fluidos exibiam permeabilidade, significativamente, menor ao vapor de água do que filmes preparados por spray. Filmes formados por spray, mediante microscopia eletrônica de varredura, apresentaram superfície áspera, possivelmente ocasionada pela imobilização prematura e associação inadequada das cadeias de polímeros.

\section{PROPRIEDADES DE TRANSPORTE DE MASSA EM POLÍMEROS}

O entendimento da resistência de filmes comestíveis ao transporte de gases, vapor ou soluto depende do conhecimento dos coeficientes de difusão, solubilidade e permeabilidade, os quais descrevem as propriedades de transporte de massa de um polímero.

O coeficiente de difusão descreve o movimento da molécula permeante pela matriz de um polímero (MILLER \& KROCHTA, 1997). Na ausência de rachaduras, cavidades ou outros defeitos, o principal mecanismo para o fluxo de gases e vapor através do filme é o de difusão ativada, que compreende a abertura de espaço vazio entre os segmentos da cadeia dos polímeros, devido as oscilações dos segmentos, seguido pelo deslocamento do permeante dentro do espaço vazio, antes dos segmentos retornarem ao seu estado normal (KESTER \& FENNEMA, 1986; MILLER \& KROCHTA, 1997). O coeficiente de solubilidade descreve a dissolução do permeante num polímero e o coeficiente de permeabilidade, que consiste na taxa de transporte da molécula do permeante através do polímero, é o 
resultado dos efeitos combinados da difusão e solubilidade (MILLER \& KROCHTA, 1997).

A difusão ativada, principal mecanismo para o fluxo de gases e vapor, mostra-se dependente da estrutura do polímero para realizar o transporte do permeante, uma vez que esta afeta diretamente a mobilidade dos segmentos das cadeias. Fatores que alteram a estrutura do polímero, influenciam suas propriedades de transporte de massa. Várias propriedades dos polímeros influenciam a sua permeabilidade, tais como: estrutura química, densidade de energia coesiva, volume livre, cristalinidade, polaridade, ligação cruzada, orientação, método de formação do polímero, condições de processamento, presença de aditivos e combinação de polímeros (JASSE, SEUVRE \& MATHLOUTHI, 1994).

\subsection{ESTRUTURA QUÍMICA}

O conhecimento dos efeitos da variação das estruturas químicas nas propriedades de transporte de massa de um polímero torna-se necessário, já que os tipos de grupos substituintes afetam o coeficiente de permeabilidade do polímero, por influenciarem a firmeza da ligação das cadeias e a quantidade de volume livre existente entre estas (MILLER \& KROCHTA, 1997).

\subsection{DENSIDADE DA ENERGIA COESIVA (DEC)}

A DEC compreende a medida da polaridade do polímero e da energia de ligação das cadeias dos polímeros. Em geral, quanto mais alta a DEC dos polímeros, maior dificuldade existe na abertura da cadeia do polímero e na permissão da passagem do permeante (exceto para permeantes altamentes polares, como a água). Devido a polaridade da molécula da água, esta não depende da "abertura" da cadeia de polímeros, pois a água pode forçar a abertura das cadeias para propiciar a formação de uma ponte de hidrogênio, mesmo em DEC alta (MILLER \& KROCHTA, 1997).

\subsection{VOLUME LIVRE}

Volume livre é a medida do grau do espaço intersticial entre as moléculas do polímero (MAEDA \& PAUL, 1987). A adição de plasticizantes ao polímero para aumentar o volume livre resulta em menor temperatura de transição vítrea. A adição de anti-plasticizantes para diminuir o volume livre aumenta a temperatura de transição vítrea, segundo MAEDA \& PAUL, 1987. Polímeros ligados fortemente que apresentam alta temperatura de transição vítrea, geralmente evidenciam baixa permeabilidade a gases, a não ser que estes também apresentem alto volume livre (MILLER \& KROCHTA, 1997). 


\subsection{CRISTALINIDADE}

A cristalinidade é definida como a medida de grau da ordem das moléculas no polímero. A cristalinidade é afetada pela regularidade estrutural e mobilidade das cadeias de polímero, pela presença de cadeias laterais repetidas, que permitem ligações intermoleculares, e pela ausência de cadeias laterais carregadas, que interferem na formação de cristal. Em polímeros semi-cristalinos, a transferência de massa de gás ou aroma se deve a fase amorfa, pois a fase cristalina normalmente assume ser impermeável. A medida que o percentual de cristalinidade do polímero aumenta, a permeabilidade deste ao oxigênio diminui (MILLER \& KROCHTA, 1997).

\subsection{ORIENTAÇÃO}

A orientação refere-se ao alinhamento das cadeias de polímeros no plano do principal polímero (MILLER \& KROCHTA, 1997). Segundo SHA \& HARRISSON, citados por MILLER \& KROCHTA (1997), a diminuição no volume livre fracional da região amorfa com orientação correlacionam-se bem com o decréscimo nos coeficientes de permeabilidade, solubilidade e difusidade.

\subsection{LIGAÇÕES CRUZADAS}

As ligações cruzadas correspondem a formação de ligações intermoleculares entre as cadeias dos polímeros (MILLER \& KROCHTA, 1997). Quando filmes de proteína de soja (GENNADIOS et al., 1996) e filmes de proteína do soro foram submetidos a "Heat Curing" obteve-se decréscimo da permeabilidade dos fillmes ao vapor de água, resultado atribuído ao aumento das ligações cruzadas intermoleculares entre os cordões de proteína durante o aquecimento.

\section{TIPOS DE FILMES E PROPRIEDADES IMPORTANTES}

\subsection{FILMES DE POLISSACARÍDIOS}

Alguns polissacarídios, tais como alginato, pectina, carragenana, amido, amido hidrolisado e derivados da celulose têm sido estudados, para seu uso potencial como revestimentos comestíveis. No entanto, espera-se mínima propriedade de barreira contra umidade nestes filmes, devido a sua natureza hidrofílica. Contudo, alguns filmes de polissacarídios podem retardar a perda de umidade de alguns alimentos, quando aplicados na forma de gel, que age como agente sacrificante, ou seja, a umidade do gel 
evapora antes da desidratação do alimento revestido (KESTER \& FENNEMA, 1986).

De acordo com BANKER (1966) observa-se, às vezes, relação inversa entre a permeabilidade ao vapor de água e a permeabilidade ao oxigênio, então certos filmes de polissacarídios podem prover proteção efetiva dos alimentos quanto às alterações provocadas pela ação do oxigênio.

\subsubsection{Alginato de sódio}

O sal do ácido algínico é um ácido poliurônico linear com ligações $\alpha 1 \rightarrow 4$, extraído da alga marrom. No ácido algínico existem 3 tipos de segmentos de polímeros: poli $\beta$-D-ácido manurônico $(M)$, poli- $\alpha$-L-ácido gulurônico $(G)$ e segmentos com resíduos alternados de ácidos D-manurônico e Lgulurônico (KING, 1983).

Os filmes de alginato podem ser formados por gelatinização, evaporação, ligação cruzada eletrolítica ou injeção de líquido miscível não-solvente por alginato (KELCO, 1976).

Para produzir o gel que é usado na formação dos filmes, o alginato deve reagir com cátions polivalentes, sendo os íons de cálcio os agentes gelificantes mais efetivos (ALLEN et al., 1963a). O mecanismo de gelatinização com cálcio envolve associação de segmentos de polímeros M (poli- $\beta$-D-ácido manurônico) e G (poli- $\alpha$-L-ácido gulurônico) para formar estruturas agregadas com íons de cálcio.

Os íons de cálcio têm por função manter as cadeias de alginato juntas pelas interações iônicas, após a formação de pontes de hidrogênio entre as cadeias, produzindo gel com estrutura de rede tridimensional (KING, 1983).

Carnes bovina e suína receberam revestimento de alginato gelatinizado, mediante da imersão das carnes na solução de alginato de sódio ou pulverização das carnes e indução da gelatinização por aplicação de solução de cloreto de cálcio.

Resultados demonstraram que a desidratação de carnes tratadas com alginato foi menor do que em amostras-controles de carnes que não receberam revestimento (ALLEN et al., 1963b; LAZARUS et al., 1976; WILLIAMS, OBLINGER \& WEST, 1978).

Embora revestimentos de alginato gelatinizado apresentem limitada resistência ao transporte de umidade (ALLEN, 1963a), sua eficácia surge do seu alto teor de umidade, devido a sua ação como agente sacrificante. 


\subsubsection{Pectina}

A pectina é um polissacarídio estrutural das células vegetais, composto de polímeros de ácido D-galacturônico com vários graus de metilesterificação. A desesterificação química da pectina resulta em pectina de baixo teor de metoxilação, que em meio aquoso forma gel na presença de íons de cálcio (MIERS et al., 1953). O cálcio iônico liga os grupos carboxílicos livres a moléculas dos polímeros adjacentes, que quando alinhadas, a associação é fortalecida por pontes de hidrogênio (KESTER \& FENNEMA, 1986).

Tal como revestimento de alginato, revestimento de gel de pectina retarda a perda de água de alimentos recobertos, por sua ação como agente sacrificante (KESTER \& FENNEMA, 1986).

\subsubsection{Carragenana}

Extrato de algas vermelhas, a carragenana consiste numa família de polissacarídios sulfatados de D-galactose e 3,6 anidro-D-galactose. A gelatinização ocorre, quando uma solução aquosa do polímero sofre resfriamento, presumivelmente pela formação de estrutura dupla-hélice para produzir rede polimérica tridimensional (GLICKSMAN, 1982; 1983).

O gel de carragenana, também atua como agente sacrificante para retardar a perda de umidade de alimentos revestidos (KESTER \& FENNEMA, 1986).

\subsubsection{Amido}

O amido de milho normal é formado por $25 \%$ de amilose e $75 \%$ de amilopectina, aproximadamente. A amilose é uma cadeia linear de resíduos de D-glicose (ligações glicosídicas $\alpha 1 \rightarrow 4$ ). A amilopectina é cadeia ramificada formada por unidades de glicose ligadas por ligações $\alpha 1$ $\rightarrow 4$ e $\alpha 1 \rightarrow 6$. Algumas variedades de milho apresentam teor de amilose acima de $85 \%$.

Filmes produzidos com solução aquosa de amilose gelatinizada, seguida da evaporação do solvente, apresentaram baixa permeabilidade ao oxigênio a baixas taxas de umidade relativa (WOLFF et al., 1951; RANKING, WOLFF \& RIST, 1958). Filmes produzidos de amido hidroxipropilado não apresentam resistência à passagem de vapor de água, no entanto, como em filmes de amilose pura apresentam resistência ao transporte de oxigênio (JOKAY, NELSON \& POWELL, 1967). 


\subsubsection{Dextrinas}

Segundo KESTER \& FENNEMA (1986) tem sido sugerido o uso de amidos hidrolisados de baixa dextrose equivalente (DE) como revestimento de proteção, devido a resistência que apresentam ao transporte de água, apesar de sua natureza hidrofílica.

Estudos realizados por ALLEN et al. (1963a) mostraram que filmes de dextrina de baixa DE e filmes de xarope de milho foram 2 ou 3 vezes mais resistentes ao transporte de vapor de água do que filmes de amido, que apresentam resistência mínima.

MURRAY \& LUFT (1973) verificaram que, mediante imersão de fatias de maçãs frescas numa solução de $40 \%$ de amido 15-DE hidrolisado antes da desidratação, preveniu o escurecimento do tecido. O resultado foi atribuído ao retardamento da entrada de oxigênio, demonstrando que filmes de amido hidrolisado apresentam alguma resistência a transmissão de oxigênio.

\subsubsection{Derivados da celulose}

A celulose é composta de unidades de $\mathrm{D}$-glicose ligadas por ligações glicosídicas $\beta 1 \rightarrow 4$. Por apresentar em seu estado nativo, grupo hidroximetil do resíduo anidroglicose, localizado alternadamente sob e sobre o polímero principal, ocorre acondicionamento muito compacto das cadeias de polímeros e alta estrutura cristalina, que resiste a solvatação em meio aquoso (KESTER \& FENNEMA, 1986).

A solubilidade da celulose em água pode ser conseguida pela sua eterificação com ácido cloroacético, cloreto de metila e óxido de propileno para produzir carboximetilcelulose (CMC), metilcelulose (MC), hidroxipropilmeticelulose (HPMC) ou hidroxipropilcelulose (HPC). Os éteres de celulose apresentam excelentes características para formar filmes.

Os filmes produzidos de éteres de celulose são sensíveis a umidade, no entanto são efetivas barreiras ao oxigênio (BAKER, BALDWIN \& NISPEROS-CARRIEDO, 1994). Metilcelulose (MC) é o éter de celulose solúvel em água, menos hidrofílico, devendo por isso apresentar maior resistência a passagem do vapor de água (KESTER E FENNEMA, 1986).

Metilcelulose (MC) e hidroxipropilmetilcelulose (HPMC) apresentam habilidade para formar revestimentos gelatinosos, sob indução térmica. Devido a esta característica e a resistência a gorduras e óleos, MC e HPMC têm sido utilizados como revestimentos para diminuir a absorção de óleo durante a fritura de extrudados, batatas fritas congeladas e anéis de cebola (GOLD, 1969). Soluções aquosas de hidroxipropilcelulose (HPC) 
não formam gel sob aquecimento, mas floculam-se a $40{ }^{\circ} \mathrm{C}$ (KRUMEL \& LINDSAY, 1976).

\subsection{FILMES DE PROTEÍNAS}

As proteínas devem apresentar-se na forma aberta ou extendida para permitir a interação molecular, necessária para a formação do filme. A extensão desta interação depende da estrutura da proteína (grau de extensão da cadeia) e da seqüência dos resíduos de aminoácidos hidrofóbicos e hidrofilícos da proteína. O aumento da interação molecular da cadeia de proteína resulta em filme forte, porém, menos flexível e permeável (KROCHTA, 1997).

O grau de hidrofilicidade do resíduo de aminoácido da proteína controla a influência da umidade na propriedade de transporte de massa do filme, tornando filmes de proteína em excelente barreira para substâncias não polares, tal como o oxigênio (KROCHTA, 1997).

\subsubsection{Colágeno}

Proteína fibrosa, encontrada no tecido animal, o colágeno é o filme comestível de proteína mais usado comercialmente, pois tem sido empregado como invólucro substituto da tripa natural em salsichas (BAKER, BALDWIN \& NISPEROS-CARRIEDO, 1994).

Apesar de não haver dados disponíveis sobre a permeabilidade ao vapor de água de filmes de colágeno, sua composição não sugere que seja boa barreira para umidade. Por outro lado, filmes de colágeno apresentam-se como excelente barreira ao oxigênio a $0 \%$ de umidade relativa, mas com o aumento desta a permeabilidade ao oxigênio também aumenta (LIEBERMAN \& GILBERT, 1973).

\subsubsection{Gelatina}

A gelatina é obtida a partir da clivagem hidrolítica das cadeias de colágeno (REINECCIUS, 1994). Apresenta cadeia longa, ramificada com exposição dos grupos guanidina (básico) e carboxílico (ácido) (KESTER \& FENNEMA, 1986).

Revestimentos comestíveis com gelatina reduzem a migração de oxigênio, umidade e óleo ou podem carrear agentes antioxidantes ou antimicrobianos (KROCHTA \& DE MULDER-JOHNSTON, 1997). 


\subsubsection{Zeína do milho}

A zeína do milho tem sido utilizada comercialmente como filme comestível em vários alimentos, devido suas propriedades de barreira, de adesão de vitamina e de carreadora de agentes microbianos. Filmes de zeína são usados na indústria farmacêutica como cápsulas de revestimento para proteção e controle da liberação de flavor e aromas (GENNADIOS et al., 1994). Outras proteínas que têm sido estudadas para formação de filmes comestíveis incluem glúten do trigo, isolado protéico de soja, isolado protéico de soro e caseína. Filmes comestíveis formados com estas proteínas são geralmente obtidos de soluções etanólicas (glúten do trigo) ou soluções aquosas (isolado protéico de soja, de soro e caseína). Estes filmes apresentam propriedades mecânicas similares às dos filmes de colágeno e grande permeabilidade ao vapor de água.

A permeabilidade ao oxigênio dos filmes de glúten do trigo, isolado protéico de soja e isolado protéico de soro é quase mínima a 0-50\% de umidade relativa (KROCHTA \& DE MULDER-JOHNSTON, 1997).

\subsection{FILMES DE LIPÍDIOS}

Variados compostos lipídicos têm sido empregados como revestimentos protetores de alimentos, incluindo monoglicerídios acetilados, ceras naturais e surfactantes.

Em função da sua baixa polaridade, a principal atuação do revestimento lipídico é bloquear o transporte de umidade (KESTER \& FENNEMA, 1986).

\subsubsection{Acetilglicerídeos}

A acetilação de monoesterato de glicerol por sua reação com anidrido acético produz 1-estearodiacetina. Muitos lipídios no estado sólido podem ser esticados somente até $102 \%$ de seu comprimento original antes de fragmentarem-se. No entanto, o monoesterato de glicerol acetilado pode ser esticado acima de $800 \%$ de seu comprimento original, em função deste apresentar-se na fase sólida na forma $\alpha$-polimórfica (JACKSON \& LUTTON, 1952).

A flexibilidade do monoesterato de glicerol acetilado na forma $\alpha$-polimórfica é atribuída a desordenada rede de entrelaçamento dos cristais. Sob estiramento, a ordem da matriz cristalina é melhorada por alinhamento dos cristais adjacentes (FEUGE, 1955).

FEUGE, VICKNAIR \& LOVEGREN (1953) e LOVEGREN \& FEUGE (1954) estudaram a permeação de vapor de água através de revestimentos de 
monoesterato de glicerol acetilado. Verificaram que a medida que se aumenta o grau de acetilação, as propriedades de barreira melhoram, devido a remoção dos grupos hidroxilas livres que poderiam interagir com as moléculas de água migrante. Os filmes de monoglicerídios acetilados apresentam valores de permeabilidade ao vapor de água menores que os filmes de polissacarídios e maiores que os filmes de etil e metilcelulose (LOVEGREN \& FEUGE, 1954).

Filmes de monoglicerídios acetilados têm sido aplicados em cortes de aves e carnes vermelhas para minimizar a desidratação durante o armazenamento (ZABICK \& DAWSON, 1963).

\subsubsection{Ceras}

As ceras comestíveis apresentam maior resistência ao transporte de umidade do que muitos filmes lipídicos e não-lipídicos (KESTER \& FENNEMA, 1986).

A cera de parafina é composta pela mistura de hidrocarbonetos saturados de cadeia longa. A cera de abelha apresenta conteúdo hidrofóbico de $71 \%$ compreendendo longas cadeias de compostos éster, $15 \%$ de hidrocarbonetos de cadeia longa, $8 \%$ de ácidos graxos de cadeias longas e $6 \%$ de compostos não identificados (TULLOCH, 1970; TULLOCH \& HOFFMAN, 1972). Esta composição molecular, caracterizada pela ausência de grupos polares na cera de parafina e baixos níveis de grupos polares na cera de abelha, justifica a grande resistência destas ceras ao transporte de umidade (KESTER \& FENNEMA, 1986).

WATTERS \& BRECKKE (1961) ao compararem as propriedades de barreira contra umidade de revestimentos de cera de abelha com propriedades de outros filmes verificaram que, a permeabilidade através de filmes de cera de abelha foi 10 vezes menor que a permeabildade de filmes de monoglicerídio acetilado, que foi de 100 a 200 vezes menor que a permeabilidade de filmes de pectina e caseína.

Filmes de cera são também altamente resistentes a difusão de ânions de benzoato, o que sugere o emprego destes filmes para manter altas concentrações de preservante na superfície do produto alimentício (MOTYCKA \& NAIRN, 1978).

A aplicação de ceras ou outros filmes lipídicos em produtos perecíveis exige que estes não sejam muito impermeáveis para não interfirir na respiração aeróbica. Filmes que impedem a entrada de oxigênio ou a saída de gás carbônico podem induzir a respiração anaeróbica, que acarreta desordens fisiológicas e diminuição da vida de prateleira do produto. 


\subsubsection{Surfactantes}

Estudos realizados sobre o emprego de revestimentos com agentes ativos de superfície em alimentos mostraram que, o uso do filme reduziu a atividade de água (Aw) superficial do alimento, bem como a taxa de perda de umidade por evaporação. A Aw superficial é a atividade de água diretamente na superfície do gênero alimentício. A Aw superficial correlaciona-se com a taxa de perda de vapor de água do produto (ROTH \& LONCIN, 1984). Baixa atividade de água superficial retarda 0 crescimento microbiológico, bem como reações químicas e enzimáticas na superfície. Assim, o revestimento de alimentos com filme surfactante pode ajudar a controlar estes tipos de deterioração, devido a redução da Aw superficial (KESTER \& FENNEMA, 1986).

\section{TRANSMISSÃO DE UMIDADE E AÇÃO DOS FILMES}

Para muitas aplicações em alimentos, a característica funcional mais importante do filme ou revestimento comestível é a resistência a umidade (KESTER \& FENNEMA,1986). Os níveis críticos de Aw precisam ser mantidos em muitos alimentos, para o produto expor ótima qualidade $e$ segurança aceitável, conforme LABUZA, 1982 e LABUZA \& CONTRERASMEDELLIN, 1981. Estes mesmos autores exemplificam que alimentos secos e crocantes tornam-se amolecidos e inaceitáveis, sob o ponto de vista da textura, em valores de 0,35 a 0,5 de Aw. PARK et al. (1996), citando o trabalho de QUAST \& KAREL, afirmaram que batata palha tornase inaceitável a partir de Aw equivalente a 0,4.

Também existem valores críticos de Aw para a proliferação microbiana em alimentos (TROLLER, 1980) e reações de deterioração química e enzimática (KESTER \& FENNEMA, 1986). Bactérias, leveduras e bolores são inibidos em AW < 0,85, 0,7 e 0,6, respectivamente (TROLLER, 1980). Para alimentos secos, a estabilidade máxima ocorre próximo ao valor da monocamada de Brunauer, Emmet e Teller (BET) entre Aw de 0,2-0,3. Acima destes valores, as taxas de reações químicas e enzimáticas, tais como escurecimento enzimático e degradação de vitaminas, pigmentos e lipídios são acentuadas, evidentemente, porque existe água suficiente para dissolver e mobilizar catalisadores e reagentes (LABUZA, 1980).

As modificações na Aw ou no conteúdo de umidade do alimento podem ocorrer dentro dos próprios constituintes do alimento, como no caso de alimentos heterogêneos (pizzas com molho de tomate), ou então, entre o alimento e a atmosfera ambiente. Em ambos os casos, o principal meio é por difusão da fase de vapor, conduzida por gradiente no potencial químico da água em diferentes localizações. A umidade pode também migrar por outros mecanismos, tais como difusão líquida direcionada por um gradiente de concentração da água, movimento líquido, causado por forças capilares 
e difusão de superfície da água absorvida em interfaces sólidas (KESTER \& FENNEMA, 1986).

É mais fácil reduzir a transmissão de umidade entre o alimento e o meio ambiente do que entre os componentes do mesmo alimento. Uma das maneiras para atingí-lo é diminuir o gradiente de pressão de vapor água, principal força que impede a difusão do permeante (neste caso o vapor de água). Isto pode ser conseguido pela redução da temperatura de armazenamento e pelo ajuste dos valores da Aw dos componentes do alimento para valores mais próximos. $O$ uso de umectantes também pode contribuir para reduzir este gradiente de pressão de vapor de água, mas sua adição em alimentos é restrita, quantitativamente, e altera características sensoriais (KESTER \& FENNEMA, 1986). Outro meio para retardar o transporte de umidade entre as partes do alimento seria o uso de filme comestível entre elas (KESTER \& FENNEMA, 1989a).

KAMPER \& FENNEMA (1985) usaram filme em bicamada, composto de hidroxipropilmetilcelulose e mistura de ácido palmítico-esteárico para retardar a transferência de umidade de massa de tomate salgada para biscoitos "cream cracker" (durante 14 dias a $25^{\circ} \mathrm{C}$ e 70 dias a $-20^{\circ} \mathrm{C}$ ), mostrando seu potencial uso em alimentos congelados. Estes filmes também podem ser aplicados no caso de migração de umidade entre 0 alimento e o meio ambiente. Para isto, o filme apropriado ao produto necessita ser selecionado, considerando também suas propriedades e eficiência contra a migração de umidade. Quanto mais hidrofílico for o polímero, mais fácil será a transmissão de umidade, logo, os filmes protéicos e de polissacarídios podem não ser boa opção a priori. Entretanto, diversas alterações podem ser realizadas, como a inserção de ligações cruzadas através de cátions divalentes em filmes de polissacarídios ou com ácidos láctico e tânico em filmes de proteínas, resultando na redução à permeabilidade de umidade do filme. Isto porque as ligações cruzadas diminuem os deslocamentos segmentais da estrutura do polímero, diminuindo a difusão ativada, a solubilidade do permeante e, por conseguinte, a permeabilidade.

AVENA-BUSTILLOS et al. (1994) aumentaram em até $45 \%$ a resistência à passagem de umidade em filmes a base de caseinato de cálcio e de sódio com a adição de cera de abelha ou de ácido esteárico, contribuindo para o retardamento do aparecimento de manchas brancas, devido a desidratação da superfície de cenouras descascadas do tipo minimamente processadas. Outra forma, neste caso aplicável somente no retardamento da perda de umidade do alimento para o ambiente, seria o uso destes polímeros como agentes "doadores" de umidade, isto é, ao invés do alimento ceder sua umidade para o ambiente, o filme o faz, preservando o alimento. Presume-se então, que devido a sua baixa polaridade, os filmes lipídicos sejam os mais eficientes contra a transmissão de umidade. 
Vários compostos lipídicos têm sido utilizados como revestimento protetor, incluindo monoglicerídios acetilados, ceras naturais e surfactantes (KESTER \& FENNEMA, 1986). Infelizmente, em muitos casos ocorrem problemas de continuidade do filme lipídico na superfície do alimento, neutralizando seu poder vedante, pois ele penetra no interior do alimento e ainda modifica o sabor do produto. Uma das maneiras de contornar este problema seria a elaboração de filmes em bicamadas, geralmente a primeira hidrofílica, que preenche todos os espaços da superfície do alimento e dá força ao gel e outra lipídica, que o protegerá contra a transmissão de umidade (GREENER \& FENNEMA, 1989).

KESTER \& FENNEMA (1989a) aperfeiçoaram um filme em bicamada, substituindo os ácidos esteárico e palmítico por metilcelulose na camada lipídica. Sua permeabilidade, semelhante ao policloreto de vinila, tolera até 9 semanas a $-40{ }^{\circ} \mathrm{C}$ sem aumentar significativamente a permeabilidade ao vapor de água e suporta Aw de até 0,97.

A pesquisa de filmes resistentes a elevadas Aw é de grande importância, já que muitos alimentos alvos de potencial uso de filmes apresentam Aw superior a 0,9 , como ocorre com os molhos de tomate, usados sobre as pizzas. O problema é que vários filmes sofrem hidratação e decomposição da estrutura tridimensional, perdendo sua função em Aw acima de 0,9.

Por outro lado, KESTER \& FENNEMA (1989b) detectaram, mediante análise sensorial de pão e salsa de tomate assados (isolados por este mesmo filme) gosto amargo, possivelmente resultante do resíduo lipídico do filme após o processo de aquecimento. Também foi encontrada diferença na permeabilidade à passagem de umidade conforme a técnica de aplicação do filme em bicamada. Os aplicados diretamente na forma de spray permitiram transmissão de 4 vezes mais que a aplicação do filme previamente elaborado (GREENER \& FENNEMA, 1989).

Todos estes trabalhos mostram o potencial a ser explorado nas propriedades oferecidas por substâncias naturais ou sintéticas $e$ Geralmente Reconhecidas Como Segura (GRAS) pelo Food and Drug Admnistration (FDA) como barreira a transmissão de umidade, quer sejam lipídicas, protéicas ou polissacarídicas modificadas. Mostram ainda alguns avanços que têm sido alcançados, mas também revelam a necessidade de mais pesquisas a fim de elucidar problemas práticos desde a elaboração até a sua implementação em nível de mercado. A gama de produtos atualmente disponíveis no mercado que utiliza esta tecnologia ainda é limitada.

\section{TRANSMISSÃO DE GASES E AÇÃO DOS FILMES}

O transporte de gases como o oxigênio e o dióxido de carbono, tal como a transmissão de umidade, pode influenciar a estabilidade do 
armazenamento de alimentos, já que o oxigênio é meio de deterioração de alimentos pela oxidação de lipídios, vitaminas, pigmentos e componentes de flavor. Desta forma, o emprego de filmes comestíveis com propriedades de barreira ao oxigênio em alimentos, visa estender a vida de prateleira e reduzir o custo da embalagem (KESTER \& FENNEMA, 1986).

BANKS (1983; 1984), citado por KESTER \& FENNEMA (1986), aplicou revestimento de éster de sacarose-carboximetilcelulose (CMC) em bananas verdes. Verificou redução da permeabilidade ao oxigênio em 5 vezes e da permeabilidade ao dióxido de carbono em menos de 2 vezes, quando comparados com bananas não-revestidas. Estes resultados indicam que o revestimento é diferencialmente permeável ao oxigênio e ao dióxido de carbono. A composição interna de gases modificada das bananas revestidas diminuiu a taxa de respiração aeróbica e retardou a ascensão climatérica associada com o amadurecimento. Resultados semelhantes foram encontrados por MEHERIUK \& LAU (1988) em pêras e por BALDWIN et al. (1995) em laranjas, que empregando filmes comestíveis de CMC retardaram o amadurecimento pela diminuição do transporte de oxigênio.

PARK, CHINNAN \& CHEWFELT (1994) estudaram o efeito do filme comestível de zeína de milho na vida de prateleira e qualidade de tomates. Verificaram que o filme afetou positivamente a troca de oxigênio nos tomates, evidenciado pelo retardamento na mudança de cor, perda da firmeza e de peso durante o armazenamento, estendendo a vida de prateleira em 6 dias.

KESTER \& FENNEMA (1986) sugeriram o uso de revestimentos de frutas e vegetais com filmes comestíveis que minimizam a respiração aeróbica, como meio análogo (mais barato) ao armazenamento em atmosfera controlada, que é dispendioso. Entretanto, BANKS (1985) verificou que a modificação da composição atmosférica interna das frutas e vegetais tornou-se mais extensa com a elevação da temperatura. Assim, alimentos revestidos com filmes que controlam os níveis de gases internos apropriados ao armazenamento prolongado a temperatura de refrigeração, quando expostos as altas temperaturas encontradas durante a distribuição, podem sofrer grande modificação na sua atmosfera interna, devido ao efeito da temperatura na funcionalidade do filme.

KLOSE, MECCHI \& HANSON (1952) verificaram a efetividade de filmes de colágeno e gelatina na proteção de produtos cárneos à oxidação. Os filmes produzidos de éteres de celulose apresentam-se como barreiras moderadas ao oxigênio. Segundo MILLER \& KROCHTA (1997) a permeabilidade ao oxigênio dos filmes de metilcelulose (MC) e hidroxiproprilcelulose (HPMC) é menor que a permeabilidade ao oxigênio do filme de polietileno de baixa densidade (LDPE). Também é maior que a do policloreto de vinilideno (PVDC) e do copolímero álcool vinil etileno 
(EVOH) a $24{ }^{\circ} \mathrm{C}$ e $50 \%$ de umidade relativa. A maior permeabilidade ao oxigênio dos filmes de éteres de celulose quando comparadas ao filme de $\mathrm{EVOH}$, visto que ambos apresentam fórmula química semelhante, deve-se a presença nos éteres de celulose do anel repetido e das estruturas dos grupos laterais, que produz menor densidade de energia coesiva (DEC), maior volume livre e menor cristalinidade que aquelas do EVOH linear.

Filmes de metilcelulose apresentam menor permeabilidade ao oxigênio $\left(97 \mathrm{~cm}^{3} \mu \mathrm{m} /(\mathrm{dkPa})\right)$ do que filmes de hidroxiproprilmetilcelulose (HPMC) $\left(272 \mathrm{~cm}^{3} \mu \mathrm{m} /(\mathrm{dkPa})\right)$, devido ao grande grupo lateral do HPMC, que resulta em menor densidade de energia coesiva, maior volume livre e menor cristalinidade que os filmes de metilcelulose (MILLER \& KROCHTA, 1997).

Filmes de amido de milho com alto teor de amilose apresentam-se como moderadas a boas barreiras ao oxigênio, sendo menos permeáveis ao oxigênio que os filmes de éteres de celulose (MARK et al. 1966).

A natureza polar das proteínas confere aos seus filmes a propriedade de excelente barreira ao oxigênio (apolar), possivelmente devido a sua impermeabilidade à substâncias apolares e a alta densidade de energia coesiva que apresentam.

Filmes de colágeno apresentam permeabilidade ao oxigênio similar a dos filmes álcool vinil etileno (EVOH) e policloreto de vinilideno (PVDC) a $0 \%$ de umidade relativa, porém com o aumento desta para $50 \%$ a permeabilidade do filme de colágeno é maior que a dos filmes $\mathrm{EVOH}$ e PVDC (LIEBERMAN \& GILBERT, 1973).

Permeabilidade maior ao oxigênio é apresentada por filmes com base de zeína de milho, glúten de trigo, proteína de soja e proteína de soro, quando comparada a permeabilidade de filmes a base de colágeno a $0 \%$ de umidade relativa. Este resultado, provavelmente se deve ao fato destas proteínas apresentarem estrutura menos linear, devido a sua natureza globular, e maior porcentagem dos grupos laterais de aminoácidos que o colágeno, resultando em menor densidade de energia coesiva e maior volume livre destes filmes protéicos (MILLER \& KROCHTA, 1997).

Em relação aos filmes lipídicos, possivelmente sua baixa polaridade poderia resultar em baixa densidade de energia coesiva e conseqüentemente em alta permeabilidade ao oxigênio. Além disso, segundo os autores GREENER \& FENNEMA (1989), para obtenção de filme comestível lipídico com as propriedades desejadas, torna-se necessária a formação de camada lipídica contínua, dificultada devido a porosidade dos alimentos que faz com que o lipídio penetre, impedindo a formação da camada com o grau de continuidade necessária. 
GREENER \& FENNEMA (1989) formularam dois filmes em bicamada, ou seja, a primeira de metilcelulose e a segunda de cera de abelha. Em um filme a cera foi aplicada na forma fundida (filme de cera-M) e no outro, em solução etanólica (filme de cera-S). Verificaram que a resistência à transmissão de oxigênio foi de duas a três vezes maior para o filme de cera-S do que para o de cera-M.

\section{CONCLUSÃO}

Os filmes comestíveis já fazem parte de vários produtos manufaturados pela indústria alimentícia em nível mundial e nacional. O potencial promissor de crescimento em diversos outros segmentos da produção de alimentos depende do aperfeiçoamento e adaptação da estrutura físicoquímica e dos métodos de aplicação dos revestimentos às características composicionais dos alimentos. Estes biopolímeros podem exercer diversas funções ainda relativamente pouco exploradas, como carreador de aditivos (conservantes, flavorizantes, etc.) e agentes antimicrobianos, barreiras a óleos e gorduras, minimização de danos durante o transporte e comercialização, otimização dos efeitos de outros métodos de conservação (como na refrigeração de frutas), e ainda, redução de gastos com embalagens externas. Neste sentido, é importante conhecer cada vez mais as propriedades funcionais dos filmes em relação não apenas ao alimento, mas também aos diversos fatores ambientais a que estarão expostos, o que indica a necessidade de novas pesquisas sobre aspectos básicos e aplicados destes compostos.

\section{Abstract}

A brief bibliography review about edible films and coatings is presented, showing the production and different types of protein, lipid and starch films and coatings. Discusses the films barrier properties against oxygen transmission and water steam. Concludes that the improvement and adaptation of the physical-chemical structure and application methods of films and coatings to the compositional characteristics of products, will provide an increase to other segments of food production.

\section{REFERÊNCIAS BIBLIOGRÁFICAS}

1 ALLEN, L., NELSON, A. I., STEINBERG, M. P., McGILL, J. N. Edible corn-carbohydrate food coatings, I. Development and physical testing of a starch-algin coating. Food Technology, v. 17, p. 1437-41, 1963a.

2 ALLEN, L., NELSON, A. I., STEINBERG, M. P., McGILL, J. N. Edible corn-carbohydrate food coating, II. Evaluation on fresh meat products. Food Technology, v. 17, p. 1442, 1963b. 
ANDRES, C. Edible films have potencial for significantly improving aesthetic and nutritional content of foods. Food Processing, v. 46, n. 7, p. 102-106, 1985.

AVENA-BUSTILLOS, R. J, CISNEROS-ZEVALLOS, L. A., KROCHTA, J. M., SALTVEIT Jr., M. E. Application of casein-lipid edible film emulsions to reduce white blush on minimally processed carrots. Postharvest Biology and Technology, v. 4, p. 319-329, 1994.

5 BAKER, R. A., BALDWIN, E. A., NISPEROS-CARRIEDO, M. O. Edible coatings and films for processed foods. In: EDIBLE coatings and films to improve food quality. Lancaster : Technomic Publishing, 1994.

6 BALASUBRAMANIAM, V. M., CHINNAN, M. S., MALLIKARJUNAN, P., PHILLIPS, R. D. The effect of edible film on oil uptake and moisture retention of a deep-fat fried poultry product. Journal of Food Process Engineering, v. 20, n. 1, p. 17-29, Feb., 1997.

7 BALDWIN, E. A., NISPEROS-CARRIEDO, M., SHAW, P. E., BURNS, $J$ J. K. Effect of coatings and prolonged storage conditions on fresh orange flavor volatiles, degrees Brix and ascorbic acids levels. Journal Agricultural of Food Chemistry, v. 43, p. 1321-1331, 1995.

8 BANKER, G. S. Film coating theory and practice. Journal Pharmacology Science, v. 55, p. 81, 1966.

9 BANKS, N. H. Internal atmosphere modification in pro-long coated apples. Acta Horticultural, v. 157, p. 105, 1985.

10 FEUGE, R. O. Acetoglycerides, new fat products of potential value to the food industry. Food Technology, v. 9, p. 314, 1955.

12 FEUGE, R. O., VICKNAIR, E. J., LOVEGREN, N. V. Modification of vegetable oils, XIII. Some additional properties of acetostearin products. JAOCS, v. 30, p. 283, 1953.

13 GENNADIOS, A., McHUGH, T. H., WELLER, C. L., KROCHTA, J. M. Edible coatings and film based on proteins. In: EDIBLE coatings and films to improve food quality. Lancaster : Technomic Publishing, 1994. p. 210-277.

14 GENNADIOS, A., GHORPADE, V. M., WELLER, C. L., HANNA, M.A. Heat curing of soy protein films. ASAE, v. 39, p. 575-579, 1996. 
15 GHORPADE, V. M., GENNADIOS, A., HANNA, M. A., WELLER, C. L. Soy protein isolate/poly(ethylene oxide)films. American Association of Cereal Chemists, v. 72, n. 6, p. 559-563, 1995.

16 GLIKSMAN, M. Functional properties. In: FOOD hydrocolloids. Boca Raton : M.Glicksman, 1982. v. 1.

17 GLIKSMAN, M. Red seaweed extracts. In: FOOD hydrocolloids. Boca Raton : M.Glicksman, 1983. v. 2.

18 GOLD, W. L. Hydrocolloids surface treatment to yield french fried potato products. U.S. Patient No. 3.424, 591. [S.I.], 1969.

19 GREENER, I. K., FENNEMA, O. R. Barrier properties and surface characteristics of edible bilayer films. Journal of Food Science, v. 54, n. 6, p. 1393-1406, 1989.

20 GUILBERT, S. Technology and application of edible protective films. In: FOOD packaging and preservation: theory and practice. London : M. Mathlouthi, 1986. 371 p.

21 HARDENBURG, R. E. Wax and related coatings for horticultural products: a bibliography. Washington DC : Agricultural Research Service Bulletin, United States Departament of Agriculture, 1967. p. 15-51.

22 JACKSON, F. L, LUTTON, E. S. The polymorphism of 1-stearyl and 1-palmitydiacetin-dibutyrin, dicaproin, and 1-stearyldipropionin. Journal American Chemistry Society, v. 74, p. 4827, 1952.

23 JASSE, B., SEUVRE, A. M., MATTHLOUTHI, M. Permeability and structure in polymeric packaging materials in food packaging and preservation. London : Mathlouthi, 1994. p. 1-22.

24 JOKAY, L., NELSON, G. E., POWELL, E. L. Development of edible amylaceous coatings for foods. Food Technology, v. 21, p. 1064-7, 1967.

25 KAMPER, S. L., FENNEMA, O. Use of an edible film to maintain water vapor gradients in foods. Journal Food Science, v. 49, p. 1482, 1985.

26 KAPLAN, H. J. Washing, waxing and color-adding. In: FRESH citrus fruits. Westport : W.F. Wardowski, 1986. p. 379.

27 KELCO, A. Algin, hydrophilic derivates of alginic acid for scientific water control. 2. ed. San Diego : Kelco, Div. of Merck \& Co., 1976. 
28 KESTER, J.J., FENNEMA, O. R. Edible films and coatings: a review. Food Technology, v. 10, n. 12, p. 47-59, Dec.1986.

29 KESTER, J. J., FENNEMA, O. R. An edible film of lipids and cellulose ethers: barrier properties to moisture vapor transmission and estructural evaluation. Journal of Food Science, v. 54, n. 6, p. 1383-1389, Nov./Dec.1989a.

30 KESTER, J. J., FENNEMA, O. R. An edible film of lipids and cellulose ethers: performance in model frozen-food system. Journal of Food Science, v. 54, n. 6, p. 1390-1393, Nov./Dec.1989b.

31 KING, A. H. Brow seawed extracts (Alginates). In: FOOD hydrocolloids. Boca Raton : M.Glicksman, 1983. v. 2.

32 KLOSE, A. A., MECCHI, E. P., HANSON, H. L. Use of antioxidants in the froozen storage of turkeys. Food Technology, v. 6, p. 308, 1952.

33 KONDO, A., VALKENBURG, J. W. Microcapsule processing and technology. New York: Marcel Dekker, 1979.

34 KROCHTA, J.M. Edible protein films and coatings in food proteins and their applications in foods. New York : Marcel Dekker, 1997. p. 529-550.

35 KROCHTA, J. M., DE MULDER-JOHNSTON, C. Edible and biodegradable polymer films: challenges and opportunities. Food Technology, v. 51, n. 2, p. 60-74, Feb. 1997.

36 KRUMEL, K. L., LINDSAY, T. A. Nonionic cellulose ethers. Food Technology, v. 30, n. 4, p. 36-43, 1976.

37 LABUZA, T. P., CONTRERAS-MEDELLIN, R. Prediction of moisture protection requirements for foods. Cereal Foods World, v. 26, p. 335, 1981.

38 LABUZA, T. P. Moisture gain and loss in packaged foods. Food Technology, v. 36, n. 4, p. 92-97, 1982.

39 LABUZA, T. P. The effects of water activity on reaction kinetic of food deterioration. Food Technology, v. 34, n. 4, p. 36-41, 1980.

40 LAZARUS, C. R., WEST, R. L., OBLINGER, J. L., PALMER, A. Z. Evaluation of a calcium alginate coating and a protective plastic wrapping for the control of lamb carcass shrinkage. Journal Food Science, v. 41, p. 639-641, 1976. 
41 LIEBERMAN, E. R., GILBERT, S. G. Gas permeation of collagen films as affected by cross-linkage, moisture, and plasticizer content. Journal Polymeric Science, n. 41, p. 33-43, 1973.

42 LOVERGREN, N. V., FEUGE, R. O. Permeability of acetostearin products to water vapor. Journal Agricultural of Food Chemistry, v. 2, p. 558, 1954.

43 MAEDA,Y., PAUL, D. R. Effect of antiplasticization on gas sorption and transport in free volume interpretation. Journal Polymeric Science, Polymeric Physical, v. 25, p. 1005-1016, 1987.

44 MARK, A. M., ROTH, W. B., MEHLTRETTER, C. L., RIST, C. E. Oxigen permeability of amylomaize starch films. Food Technology, v . 20, p. 75-77, 1966.

45 MEHERIUK, M., LAU, O. L. Effect of two polymeric coatings on food quality of "Barlett" and "d'Anjou Pears". Journal American Society Horticultural Science, v. 113, p. 222-226, 1988.

46 MIERS, J. C., SWENSON, H. A., SCHULTZ, T. H., OWENS, H. S. Pectinate and pectate coating, I. General requirements and procedures. Food Technology, v. 7, p. 229, 1953.

47 MILLER, K. S., KROCHTA, J. M. Oxygen and aroma barrier properties of edible films: a review. Food Science and Technology, v. 8, n. 7, p. 228-237, Jul., 1997.

48 MOTYCKA, S., NAIRN, J. G. Influence of max coating on release rate of anions from ion-exchange resin beads. Journal Phamacology Science, v. 67, p. 500, 1978.

49 MURRAY, D. G., LUFT, L. R., LOW, D. E. Corn starch hydrolysates. Food Technology, v. 27, n. 3, p. 32, 1973.

50 NELSON, K. L., FENNEMA, O. R. Methylcellulose films to prevent lipid migration in confectionery products. Journal of Food Science, v. 56, n. 2, p. 504-509, Mar.-Apr. 1991.

51 PARK, H. J., CHINNAN, M. S., CHEWFELT, R. L. Edible coatings effects on storage life and quality of tomatoes. Journal of Food Science, v. 59, p. 568-570, 1994.

52 PARK, J. W., TESTIN, R. F., VERGANO, P. J., PARK, H. J., WELLER, C. L. Application of laminated edible films to potato chip packaging. Journal of Food Science, v. 61, n. 4, p. 766768,777, Jul./Aug. 1996. 
53 PICKARD, J. F., RESS, J. E., ELWORTH, P.H. Water vapour permeability of poured and sprayed polymer films. Journal Phamacology Science, v. 24 (Suplemento), p. 139, 1972.

54 RANKING, J. C., WOLFF, I. A., RIST, C. E. Permeability of amylose film to moisture vapor, selected organic vapors and common gases. Ind. Eng. Chem., v. 3, n. 1, p. 120, 1958.

55 REINECECCIUS, G. A. Flavor encapsulation. In: EDIBLE coatings and films to improve food quality. Lancaster : Technomic Publishing, 1994. p. 105-120.

56 RICO-PEÑA, D. C., TORRES, J. A. Sorbic acid and potassium sorbate permeability of an edible methylcellulose-palmitic acid: water activity and $\mathrm{pH}$ effects. Journal of Food Science, v. 56, n. 2, p. 497-499, Mar./Apr. 1991.

57 ROTH, T., LONCIN, M. Superficial activity of water. In: ENGINEERING and food. London : B.M. Mckenna, 1984. v.1.

58 SOROKA, W. Fundamental of packaging technology. Herndon : Institut of Packaging Professionals, 1995.

59 TROLLER, J. A. Influences of water activity on microorganisms in foods. Food Technology, v. 34, n. 5, p. 247, 1980.

60 TULLOCH, A. P. The composition of beeswax and other waxes secreted by insects. Lipids, v. 5, p. 247, 1970.

61 TULLOCH, A. P., HOLFMAN, L. L. Canadian beeswax: analytical values and composition of hydrocarbons, free acids, and long chain esters. JAOCS, v. 49, p. 696-699, 1972.

62 WATTERS, G. G., BREKKEK, J. E. Stabilized raisins for dry cereal products. Food Technology, v. 15, p. 236, 1961.

63 WILLIAMS, S. K., OBLINGER, J. L., WEST, R. L. Evaluation of a calcium alginate film for use on beef cuts. Journal of Food Science, v. 43, p. 292, 1978.

64 WOLFF, I. A , DAVIS, H. A., CLUSKEY, J. E., GUNDRUM, L. J., RIST, C. E. Preparation of films from amylose. Ind. Eng. Chem, v. 43, p. $915,1951$.

65 ZABIC, M. E., DAWSON, L.E. The acceptability of cooked poultry protected by an edible acetylated monoglyceride coating during fresh and frozen storage. Food Technology, v. 17, p. 87, 1963. 